\title{
Estimasi Parameter Model Moving Average Orde 1 Menggunakan Metode Momen dan Maximum Likelihood
}

\author{
Nirwana $^{a}$, Mustika Hadijati ${ }^{b}$, Nurul Fitriyani ${ }^{c}$,* \\ a Program Studi Matematika, FMIPA, Universitas Mataram, Jl. Majapahit No. 62, Mataram,83125, Indonesia. Email: \\ nirwa1209@gmail.com \\ b Program Studi Matematika, FMIPA, Universitas Mataram, Jl. Majapahit No. 62, Mataram,83125, Indonesia. Email: \\ mustika.hadijati@unram.ac.id \\ c Program Studi Matematika, FMIPA, Universitas Mataram, Jl. Majapahit No. 62, Mataram,83125, Indonesia. Email: \\ nurul.fitriyani@unram.ac.id
}

\section{A B S T R A C T}

Autoregressive Integrated Moving Average (ARIMA $(p, d, q)$ ) is a model that commonly used to model time series data. One model that can be modeled is Moving Average (MA). In this study, the estimation of parameters was performed to produce the model estimator parameter, where if the order component of the MA model is known, then the methods that can be used are the Ordinary Least Square (OLS) method, Moment method, and Maximum Likelihood method. But in fact, there are often assumption deviations when using the OLS method, one of which occurs heteroscedasticity (variant is not constant) which is produce a poor estimator. This study used both Moment and Maximum Likelihood method in estimating the parameter of the $1^{\text {st }}$ Moving Average model, denoted by MA (1). The result showed that MA (1) parameter model using Moment method gave better result than Maximum Likelihood method. This can be seen from the value of Schwartz Bayesian Criterion (SBC) of both Moment and Maximum Likelihood method parameter estimator with magnified amount of data and various parameters values generated.

Keywords: ARIMA, Maximum Likelihood Method, Moment Method, Moving Average, Parameter Estimation, SBC.

\section{Pendahuluan}

Pada tahun 1976 Box-Jenkins memperkenalkan model runtun waktu yang biasa digunakan untuk memodelkan data runtun waktu, yaitu model Autoreggressive Integrated Moving

Average (ARIMA $(p, d, q))$, dengan simbol $p$ menyatakan orde dari proses Autoregressive (AR), simbol $d$ menyatakan transformasi pembedaan (differencing), dan simbol $q$ menyatakan orde dari proses Moving Average
(MA) (Aswi dan Sukarna, 2006). Dalam suatu model ARIMA, perlu dilakukan estimasi parameter untuk memperoleh parameter modelnya. Salah satu model runtun waktu yang dapat dimodelkan adalah model Moving Average (MA).

Sementara itu, apabila orde $q$ dari proses Moving Average diketahui, maka terdapat tiga metode yang dapat diterapakan dalam estimasi parameter, yaitu metode Moment, metode Ordinary Least Square (OLS), dan metode Maximum Likelihood (Kirchgassner dan Jurgen, 2007). Akan tetapi, sering terjadi penyimpangan asumsi ketika menggunakan metode OLS, salah satunya terjadi 
heteroskedastisitas yang menyebabkan estimasi yang dihasilkan tidak bias, konsisten namun tidak efisien, sehingga estimator yang diperoleh kurang baik (Rodliyah, I., 2016). Berdasarkan uraian sebelumnya, pada tulisan ini dilakukan estimasi parameter pada model Moving Average orde 1, atau dinotasikan MA (1), dengan menggunakan metode Moment dan metode Maximum Likelihood. Selanjutnya, dilakukan pula perbandingan kedua metode tersebut dan penerapannya pada data simulasi.

\section{Analisis Runtun Waktu}

Analisis runtun waktu adalah salah satu prosedur statistika yang diterapkan untuk meramalkan struktur probabilistik keadaan yang akan terjadi di masa yang akan datang dalam rangka mengambil keputusan (Aswi dan Sukarna, 2006).

\subsection{Stasioner}

Kondisi stasioner terdiri atas dua hal, yaitu stasioner dalam rata-rata dan stasioner dalam varian. Runtun waktu dikatakan stasioner dalam rata-rata apabila rata-ratanya tidak berubah dari waktu ke waktu atau bersifat stabil (Aswi dan Sukarna, 2006). Secara umum apabila terdapat pembedaan orde $\mathrm{ke}-d$, stasioneritas dicapai dengan persamaan pembedaan (differencing) orde $\mathrm{ke}-d$ berikut.

$$
Z_{t}^{d}=(1-B)^{d} Z_{t}
$$

Selanjutnya, runtun waktu dikatakan stasioner dalam varian, apabila plot data memperlihatkan adanya perubahan varian yang jelas dari waktu ke waktu (Makridakis, dkk., 1999). Data yang belum stasioner dalam varian dilakukan dengan proses transformasi, yaitu power transformation $(\lambda)$, dengan persamaan sebagai berikut (Wei, 2006).

$$
T\left(Z_{t}\right)=\left\{\begin{array}{c}
\frac{Z_{t}^{\lambda}-1}{\lambda}, \lambda \neq 0 \\
\ln Z_{t}, \lambda=0
\end{array}\right.
$$

Suatu proses $\left\{Z_{t}\right\}$ yang stasioner mempunyai rata-rata dan varian konstan, serta kovarian yang merupakan fungsi dari pembedaan waktu $|t-s|$. Rata-rata, varian, dan kovarian yang dimaksud tersebut adalah antara lain sebagai berikut.

- Rata-rata, yaitu $E\left(Z_{t}\right)=\mu$

- Varian, yaitu $\operatorname{var}\left(Z_{t}\right)=E\left(Z_{t}-\mu\right)^{2}=\sigma^{2}$

- Kovarian, yaitu $\operatorname{cov}\left(Z_{t}, Z_{s}\right)=\gamma_{t, s}$

\subsection{Fungsi Autokorelasi (Autocorrelation Function, ACF) dan Fungsi Autokorelasi Parsial (Partial Autocorrelation Function (PACF))}

ACF merupakan suatu fungsi yang menunjukkan besarnya korelasi antara pengamatan pada waktu ke $-t$ dengan pengamatan pada waktu-waktu yang sebelumnya. Nilai fungsi autokorelasi sampel pada lag $\mathrm{ke}-k$ adalah:

$$
r_{k}=\operatorname{corr}\left(Z_{t}, Z_{t-k}\right)=\frac{\sum_{t=1}^{n-k}\left(Z_{t}-\bar{Z}\right)\left(Z_{t+k}-\bar{Z}\right)}{\sum_{t=1}^{n}\left(Z_{t}-\bar{Z}\right)^{2}}
$$

Selanjutnya, PACF digunakan untuk mengukur tingkat keeratan antara $Z_{t}$ dan $Z_{t-k}$ apabila pengaruh dari lag waktu (time lag) $1,2,3, \ldots, k-1$ dianggap terpisah. Nilai PACF sampel dinyatakan dengan persamaan berikut.

$$
\phi_{k k}=\frac{\rho_{k}-\sum_{j=1}^{k-1} \phi_{k-1, j} \rho_{k-j}}{1-\sum_{j=1}^{k-1} \phi_{k-1, j} \rho_{j}}
$$

\subsection{Metode ARIMA Box-Jenkins}

Secara umum model Autoregressive orde $p$ atau dapat ditulis $(\operatorname{AR}(p))$ mempunyai bentuk sebagai berikut.

$$
Z_{t}=\phi_{1} Z_{t-1}+\phi_{2} Z_{t-2}+\ldots+\phi_{p} Z_{t-p}+a_{t}
$$

Selanjutnya, model Moving Average orde $q$ atau dapat ditulis (MA $(q)$ ) secara umum mempunyai bentuk sebagai berikut.

$$
Z_{t}=a_{t}-\theta_{1} a_{t-1}+\theta_{2} a_{t-2}+\ldots+\theta_{q} a_{t-q}
$$

Model gabungan antara $(\operatorname{AR}(p))$ dan $(\operatorname{MA}(q))$, atau dapat ditulis $(\operatorname{ARMA}(p, q))$, mempunyai bentuk persamaan sebagai berikut.

$$
Z_{t}=\phi_{1} Z_{t-1}+\ldots+\phi_{p} Z_{t-p}+a_{t}-\theta_{1} a_{t-1}+\ldots+\theta_{q} a_{t-q}
$$

Model ARIMA pada orde $\mathrm{ke}-p, q$ dengan differencing sebanyak $d$ atau ARIMA $(p, d, q)$ memiliki bentuk umum sebagai berikut.

$$
\phi_{p}(B)(1-B)^{d} Z_{t}=\theta_{0}+\theta_{q}(B) a_{t}
$$




\subsection{Langkah-Langkah dalam Analisis Runtun Waktu}

Terdapat beberapa langkah dalam melakukan analisis runtun waktu, yaitu identifikasi model, estimasi parameter, pemeriksaan diagnostik, dan diakhiri dengan melakukan peramalan.

Identifikasi model sementara sebagai tahap awal yang dilakukan dimulai dengan menentukan kestasioneran data runtun waktu. Selanjutnya, dilakukan pembuatan grafik autokorelasi (ACF) dan grafik autokorelasi parsial (PACF) yang dapat membantu dalam penetapan orde model ARIMA yang paling tepat (Aswi dan Sukarna, 2006), yaitu dengan bantuan Tabel 1 berikut.

\section{Tabel 1 - Identifikasi Orde Model ARIMA pada ACF dan PACF}

\begin{tabular}{ccc}
\hline Model & ACF & PACF \\
\hline AR $(p)$ & Dies down & Cut off after lag $-p$ \\
MA $(q)$ & Cut off after lag $-q$ & Dies down \\
ARMA $(p, q)$ & Dies down & Dies down
\end{tabular}

Tahap selanjutnya yang dilakukan adalah estimasi parameter. Estimasi parameter dalam model merupakan perhitungan yang dilakukan untuk mendapatkan nilai parameter model, yaitu besaran dari koefisien model (Aswi dan Sukarna, 2006).

Pemeriksaan diagnostik meliputi pengujian signifikansi parameter yang diperoleh. Selanjutnya, dilakukan pengujian pengujian kesesuaian model, yaitu pengujian asumsi White Noise dengan statistik pengujian Ljung Box dan pengujian asumsi kenormalan dengan melakukan pengujian Kolmogorov Smirnov (KS).

Tahap terakhir dalam analisis runtun waktu adalah melakukan peramalan. Peramalan merupakan suatu cara yang digunakan untuk mengetahui nilai atau keadaan yang akan terjadi di masa yang akan datang dalam rangka pengambilan keputusan.

\subsection{Metode Moment dan Maximum Likelihood}

Metode Moment dilakukan dengan mensubtitusikan beberapa Moment sampel, seperti rata-rata sampel $(\bar{Z})$, varian sampel $\left(\hat{\gamma}_{0}\right)$, dan Autocorrelation Function (ACF) sampel $\left(\hat{\rho}_{k}\right)$, dalam melakukan estimasi parameter yang tidak diketahui dari persamaan yang dihasilkan (Wei, 2006).

Dalam metode Maximum Likelihood, dimisalkan $X_{1}, X_{2}, \ldots, X_{T}$ adalah sampel acak dari populasi dengan densitas $\left(X_{t} ; \vartheta\right)$, maka fungsi Likelihood didefinisikan (Bain dan Engelhardt, 1992):

$$
L\left(\vartheta_{1}, \vartheta_{2}, \ldots, \vartheta_{n}\right)=\prod_{t=1}^{T} f\left(X_{t} ; \vartheta\right)
$$

Apabila fungsi Likelihood ini terdiferensialkan maka estimator Likelihood yang mungkin adalah:

$$
\frac{\partial L(\vartheta)}{\partial \vartheta}=0
$$

Untuk membuktikan bahwa $\vartheta$ benar-benar memaksimumkan fungsi Likelihood $L(\vartheta)$ harus ditunjukkan bahwa:

$$
\frac{\partial^{2} L(\vartheta)}{\partial \vartheta^{2}}<0
$$

\subsection{Pemilihan Model Terbaik}

Salah satu kriteria pemilihan model terbaik adalah Schwartz Bayesian Criterion (SBC). SBC merupakan kriteria yang dapat dirumuskan dengan persamaan sebagai berikut.

$$
S B C=n \times \ln (S S E / n)+f \ln (n)+n \times \ln (2 \pi)
$$

\section{Metodologi}

Berdasarkan uraian sebelumnya, pada tulisan ini dilakukan estimasi parameter pada model Moving Average orde 1, atau dinotasikan MA (1), dengan menggunakan metode Moment dan metode Maximum Likelihood. Selanjutnya, dilakukan pula perbandingan kedua metode tersebut dan penerapannya pada data simulasi.

Pada tahap ini, data yang digunakan adalah data simulasi yang dibangkitkan dengan menggunakan beberapa model Moving Average dengan beberapa parameter tertentu, yang diharapkan dapat mewakili model-model ARIMA secara umum.

Langkah-langkah untuk mencapai tujuan penelitian diberikan sebagai berikut.

(a) Studi literatur;

(b) Estimasi parameter model Moving Average menggunakan masing-masing metode Moment dan metode Maximum Likelihood, yaitu dengan langkahlangkah sebagai berikut.

1) Mengambil sampel $n$; 
2) Mengecek stasioneritas, baik terhadap rata-rata maupun terhadap varians data tersebut. Apabila kondisi ketidakstasioneran terjadi dalam varians, dilakukan proses transformasi. Sebaliknya, apabila kondisi ketidakstasioneran terjadi dalam rata-rata, dilakukan proses differencing;

3) Mengidentifikasi model Moving Average;

4) Estimasi parameter model Moving Average, dengan masing-masing metode, diperoleh $\hat{\theta}$;

5) Membandingkan hasil estimasi parameter model Moving Average dengan metode Moment dan metode Maximum Likelihood, yaitu dengan membandingkan nilai Schwartz Bayesian Criterion (SBC);

(c) Penerapan prosedur estimasi pada data simulasi;

1) Membangkitkan data runtun waktu dengan beberapa ukuran sampel yang berbeda dan nilai parameter yang bervariasi;

2) Menentukan estimator parameter model Moving Average dari data yang telah dibangkitkan, masing-masing dengan menggunakan metode Moment dan metode Maximum Likelihood;

3) Membandingan nilai Schwartz Bayesian Criterion $(S B C)$ dari estimator-estimator yang telah diestimasi menggunakan metode Moment dan metode Maximum Likelihood;

(d) Penarikan Kesimpulan.

\section{Hasil dan Pembahasan}

Estimasi parameter model Moving Average orde 1, MA (1), dilakukan menggunakan metode Moment dan metode Maximum Likelihood. Hasil estimasi model MA (1) yang diperoleh menggunakan metode Moment, yaitu:

$$
\begin{aligned}
\hat{\theta}_{1} & =\frac{-b \pm \sqrt{\left(b^{2}-4 a c\right)}}{2 a} \\
& =\frac{-1 \pm \sqrt{\left(1-4 r_{1}^{2}\right)}}{2 r_{1}}
\end{aligned}
$$

Selanjutnya, estimasi parameter menggunakan metode Maximum Likelihood pada model MA $(q)$ secara umum menghasilkan nilai fungsi likelihood, yaitu:

$$
L\left(\mu, \theta, \sigma_{a}^{2} \mid Z_{t}\right)=\left(2 \pi \sigma_{a}^{2}\right)^{-\frac{T}{2}} \exp \left(-\frac{S(\mu, \theta)}{2 \sigma_{a}^{2}}\right)
$$

$$
S(\mu, \theta)=\sum_{t=1}^{T}\left(Z_{t}-\theta_{1} a_{t-1}-\ldots-\theta_{q} a_{t-q}\right)^{2}
$$

Log-likelihood dari persamaan (15) diberikan sebagai berikut.

$$
l\left(\mu, \theta, \sigma_{a}^{2} \mid Z_{t}\right)=-\frac{T}{2} \log 2 \pi-\frac{T}{2} \log \sigma_{a}^{2}-\frac{1}{2 \sigma_{a}^{2}} S(\mu, \theta)
$$

Selanjutnya, ditentukan turunan log-likelihood terhadap masing-masing parameter $\mu, \theta$, dan $\sigma_{a}^{2}$. Berikut estimator parameter $\sigma_{a}^{2}$ yang diperoleh dengan menurunkan log-likelihood, yaitu:

$$
\hat{\sigma}_{a}^{2}=\frac{\sum_{t=1}^{T} a_{t}^{2}}{T}
$$

Dengan cara yang sama dilakukan untuk memperoleh parameter $\theta_{1}$ yaitu dengan menurunkan log-likelihood terhadap parameter $\theta_{1}$. Adapun hasil estimator untuk model MA (1), yaitu:

$$
\hat{\theta}_{1}=\frac{\sum_{t=1}^{T} Z_{t} a_{t-1}}{\sum_{t=1}^{T} a_{t-1}^{2}}
$$

Nilai SBC dari estimator $\hat{\theta}_{1}$ pada model MA (1) dengan metode Moment berdasarkan persamaan (12) adalah:

$$
\begin{aligned}
S B C & =n \times \ln \left[\frac{\sum_{t=1}^{n}\left(Z_{t}-\hat{a}_{t}+\left(\frac{-1 \pm \sqrt{\left(1-4 r_{1}^{2}\right.}}{2 r_{1}}\right) \hat{a}_{t-1}\right)^{2}}{n}\right] \\
& +f \ln (n)+n \times \ln (2 \pi)
\end{aligned}
$$

Selanjutnya, nilai SBC dari estimator $\hat{\theta}_{1}$ pada model MA (1) dengan metode Maximum Likelihood berdasarkan persamaan (12) adalah:

dengan, 


$$
\begin{aligned}
& S B C=n \times \ln \left[\frac{\sum_{t=1}^{T}\left(Z_{t}-\hat{a}_{t}+\left(\frac{\sum_{t=1}^{T} Z_{t} a_{t-1}}{\sum_{t=1}^{T} a_{t-1}^{2}}\right)^{2} \hat{a}_{t-1}\right.}{n}\right] \\
& +f \ln (n)+n \times \ln (2 \pi)
\end{aligned}
$$

Berdasarkan Persamaan (19) dan Persamaan (20), terlihat bahwa unsur berbeda terletak pada nilai SSE, yaitu pada masing-masing nilai estimator $\hat{\theta}_{1}$, yaitu:

$$
-1 \pm \sqrt{\left(1-4 r_{1}^{2}\right)} / 2 r_{1}
$$

dan

$$
\sum_{t=1}^{T} Z_{t} a_{t-1} / \sum_{t=1}^{T} a_{t-1}^{2}
$$

Persamaan (21) dan Persamaan (22) menunjukkan pola yang relatif rumit dalam mendukung peneliti dalam membuat kesimpulan mengenai hasil akhir yang diperoleh. Oleh karena itu, secara teoritis, belum dapat diketahui metode mana yang terbaik diantara metode Moment dan metode Maximum Likelihood dengan memperhatikan persamaan Schwartz Bayesian Criterion (SBC) yang diperoleh.

Selanjutnya, penerapan estimasi parameter pada data simulasi dilakukan dengan membangkitkan data beberapa ukuran sampel yang berbeda dan nilai parameter yang bervariasi. Proses perbandingan hasil estimasi dilakukan dengan tujuan untuk mengetahui metode mana yang terbaik yang dapat dijadikan sebagai alternatif di dalam estimasi parameter model Moving Average dengan orde 1, atau MA (1).

Tabel 2 menunjukkan nilai estimasi parameter model MA (1) dan nilai SBC masing-masing metode Moment dan metode Maximum Likelihood yang dihasilkan. Berdasarkan nilai SBC yang diperoleh, dapat diketahui bahwa nilai SBC yang dihasilkan pada estimasi parameter menggunakan metode Moment memberikan nilai yang lebih kecil dibandingkan dengan metode Maximum Likelihood.

Oleh karena itu, dapat disimpulkan bahwa metode Moment memberikan hasil yang lebih baik dibandingkan metode Maximum Likelihood pada model MA (1) dengan beberapa ukuran sampel yang berbeda dan nilai parameter yang bervariasi dari data yang dibangkitkan.
Tabel 2 - Ringkasan Hasil Estimasi Parameter dan

\begin{tabular}{|c|c|c|c|c|}
\hline \multirow{2}{*}{$\theta_{1}$} & \multicolumn{2}{|c|}{ Estimator } & \multicolumn{2}{|c|}{ Nilai SBC } \\
\hline & Moment & $\begin{array}{l}\text { Maximum } \\
\text { Likelihood }\end{array}$ & Moment & $\begin{array}{l}\text { Maximum } \\
\text { Likelihood }\end{array}$ \\
\hline \multicolumn{5}{|c|}{$n=50$} \\
\hline 0.10 & 0.6620 & -1.0123 & -157.29 & 31.066 \\
\hline 0.25 & 0.6028 & -0.8569 & -193.24 & -33.649 \\
\hline 0.50 & 0.8962 & -0.9458 & -503.96 & -199.621 \\
\hline 0.75 & 0.5419 & -0.1711 & -275.34 & -180.139 \\
\hline \multicolumn{5}{|c|}{$n=250$} \\
\hline 0.10 & 0.5239 & -0.8864 & -1831.94 & -1134.792 \\
\hline 0.25 & 0.7239 & -0.9879 & -1439.10 & -432.403 \\
\hline 0.50 & 0.7050 & -1.0021 & -1705.15 & -729.499 \\
\hline 0.75 & 0.5038 & -0.9424 & -1355.13 & -662.417 \\
\hline \multicolumn{5}{|c|}{$n=1000$} \\
\hline 0.10 & 0.8583 & -1.0230 & -13189.62 & -7796.886 \\
\hline 0.25 & 0.8407 & -1.0246 & -10105.49 & -4939.307 \\
\hline 0.50 & 0.9305 & -0.9592 & -10410.54 & -3573.374 \\
\hline 0.75 & 0.7956 & -0.9719 & -10493.35 & -5860.621 \\
\hline
\end{tabular}
Nilai SBC Model MA (1) Menggunakan Metode Moment dan Metode Maximum Likelihood

\section{Kesimpulan}

Secara teoritis, belum dapat diketahui metode mana yang terbaik diantara metode Moment dan metode Maximum Likelihood dengan memperhatikan persamaan SBC yang diperoleh. Selanjutnya, penerapan estimasi parameter pada data simulasi menunjukkan bahwa metode Moment memberikan hasil yang lebih baik dibandingkan metode Maximum Likelihood pada model MA (1) dengan beberapa ukuran sampel yang berbeda dan nilai parameter yang bervariasi dari data yang dibangkitkan.

\section{DAFTAR PUSTAKA}

Aswi dan Sukarna (2006). Analisis Deret Waktu. Makasar: Andira Publisher.

Kirchgassner, G., dan Jurgen W. (2007) Introduction to Modern Time Series Analysis. Berlin: Springer-Verlag.

Rodliyah, I. (2016). Perbandingan Metode Bootstrap dan Jackknife dalam Mengestimasi Parameter Regresi Linier Berganda, Jurnal Matematika dan Pendidikan Matematika, Vol 1, No 1, 77.

Makridakis, S., Steven C., dan Wheelwrigth, V. (1999) Metode dan Aplikasi Peramalan Edisi Kedua. Terjemahan Andriyanto, Sus, U., dan Basith, A., Jakarta: Erlangga. 
Wei, W.W.S. (2006) Time Series Analysis Univariate and Multivariate Methods. California: Addison-Wesley Publishing Company.

Yamin, M. (2015) Peramalan Pola Data Musiman dengan Model Winter's dan ARIMA., Vol 11, No 1, 73.
Bain L.J., dan Engelhardt, M. (1992) Introduction to Probability and Mathematical Statistics. California: Duxbury Press. 